\title{
The role of the meningeal lymphatic system in local inflammation and trigeminal nociception implicated in migraine pain
}

$1 \quad$ Nikita Mikhailov ${ }^{1}$, Kseniia Koroleva ${ }^{1,3}$, Ali Abdollahzadeh ${ }^{1}$, Raisa Giniatullina ${ }^{1}$, Oleg

2 Gafurov $^{3}$, Tarja Malm¹, Alejandra Sierra ${ }^{1}$, Jussi Tohka ${ }^{1}$, Francesco Noe ${ }^{2 \#}$, Rashid

3 Giniatullin ${ }^{1,3}$

$4{ }^{1}$ A. I. Virtanen Institute for Molecular Sciences, University of Eastern Finland, Kuopio,

570211 , Finland

$6 \quad{ }^{2}$ HiLIFE-Neuroscience Center, University of Helsinki, Helsinki, 00290, Finland

$7 \quad{ }^{3}$ Laboratory of Neurobiology, Kazan Federal University, Kazan 420008, Russia

$8 \quad$ \# Shared last authorship

9 *Correspondence:

10 Francesco Noe, Neuroscience Center, HiLife, Helsinki University, Biomedicum A-wing,

11 Haartmaninkatu 8, P.O.Box 69, Helsinki 00290, Finland, e-mail: francesco.noe@helsinki.fi

12 Keywords: meningeal lymphatic, neuroinflammation, migraine, pain

13 Abstract

14 Background: A system of lymphatic vessels has been recently characterized in the

15 meninges, with a postulated role in 'cleaning' the brain via cerebral fluid drainage. As

16 meninges are the origin site of migraine pain, we hypothesized that malfunctioning of the

17 lymphatic system should affect the local trigeminal nociception. To test this hypothesis, we

18 studied nociceptive and inflammatory mechanisms in the meninges of K14-VEGFR3-Ig mice

19 lacking the meningeal lymphatic system.

20 Methods: We recorded the spiking activity of meningeal afferents and estimated the local

21 mast cells infiltration, calcitonin gene-related peptide (CGRP) and cytokine levels (basal and

22 stimulated), as well as the dural trigeminal innervation in freshly-isolated hemiskull

23 preparations from K14-VEGFR3-Ig (K14) or wild type C57BL/6 mice (WT).

24 Results: We found that the meningeal level of CGRP and of the pro-inflammatory cytokines

25 IL12-p70 and TNF $\alpha$ (implicated in migraine) were reduced in the meninges of K14 mice. On

26 the contrary, in the meninges of K14 mice, we found an increased level of the mast cell

27 activator MCP-1 and, consistently, a larger number of dural mast cells. The other migraine-

28 related pro-inflammatory cytokines did not differ between the two genotypes. The patterns of 


\section{Meningeal lymphatics in migraine}

29 trigeminal innervation in meninges remained unchanged and we did not observe alterations in basal or ATP-induced nociceptive firing in the meningeal afferents.

31 Conclusions: In summary, the lack of meningeal lymphatic system does not induce migraine-like nociceptive state per se, but leads to a new balance between pro- and antiinflammatory factors implicated in migraine mechanisms.

\section{Abbreviations:}

WT - wild type mice

K14 - K14-VEGFR3-Ig mice

mLVs - meningeal lymphatic vessels

\section{Introduction}

39 Migraine is a complex neurological disorder, which originates from the meninges (Bolay et al., 2002; Olesen et al., 2009). Meninges are densely innervated by somatic trigeminal (Ramachandran, 2018; Zakharov et al., 2015) and parasympathetic innervation (Delépine and Aubineau, 1997), which runs along and in contact with meningeal blood vessels (Ebersberger et al., 2006). It has been proposed that so-called sterile neurogenic inflammation (Moskowitz, 1993, 1984; Moskowitz et al., 1979) in the meninges is an important initiator of the pathophysiology of migraine. The initial step in neurogenic inflammation is the activation of the trigeminal nociceptive system in meninges (Moskowitz, 1993). Indeed, trigeminal neurons release the calcitonin gene-related neuro-peptide (CGRP), which activates dural mast cells (Ottosson and Edvinsson, 1997), promotes sensitization of trigeminal afferents (Cady et al., 2011; Giniatullin et al., 2008), and induces local vasodilation (Goadsby et al., 1988). Vasodilation, in turn, activates mechanosensitive receptors, expressed in trigeminal nerves within the meninges (Mikhailov et al., 2019). Trigeminal neurons can also be activated by mast cells-secreted serotonin (Kilinc et al., 2017), and by extracellular ATP, which is released from endothelial and mast cells, as well as from neurons, upon stimulation of the migraine mediator

54 CGRP (Koroleva et al., 2019; Suleimanova et al., 2020; Yegutkin et al., 2016). Finally, the release of acetylcholine (ACh) by parasympathetic fibers results in meningeal mast cell degranulation (Shelukhina et al., 2017), which activates the trigeminal nociceptive system. In addition, endothelial (Loberg et al., 2006) and mast cells (Mukai et al., 2018) release various pro-inflammatory cytokines as potential contributors to local inflammation.

The presence of these diverse endogenous agents in the meninges suggests the existence of

60 regulatory mechanisms, which modulates the local levels of pro-inflammatory mediators and

61 minimize the activity of nociceptive fibers. The recently characterized meningeal lymphatic 


\section{Meningeal lymphatics in migraine}

system (Antila et al., 2017; Aspelund et al., 2015; Louveau et al., 2015) (Figure 1) has been suggested to play a role in the clearance of the central nervous system (CNS) from toxic molecules, and to be involved in the pathogenesis of different neurodegenerative diseases (Kwon et al., 2019; Noé and Marchi, 2019; Patel et al., 2019; Rasmussen et al., 2018; Tamura et al., 2019). We hypothesized that the meningeal lymphatic vessels (mLVs) can play a similar role also in the meninges, clearing the pro-inflammatory mediators. We also hypothesize that dysfunction in the lymphatic drainage can trigger migraine.

\section{Methods and materials}

\subsection{Animals}

We used adult (30 - $40 \mathrm{~g}$ ) male and female transgenic K14-VEGFR3-Ig (K14) mice lacking the meningeal lymphatic system (Aspelund et al., 2015; Mäkinen et al., 2001) and wild-type C57BL/6J littermates mice (WT). Total number of animal used for this study was $38 \mathrm{WT}$ and 37 TG animals. Animals were housed at the Lab Animal Center of the University of Eastern Finland under following housing conditions: 12 hours dark/light cycle, grouped housing, given ad libitum access to food and water, $22^{\circ} \mathrm{C}$ ambient temperature. All procedures with animals were conducted in accordance with the European Community Council Directive 2010/63/EU. Experimental protocols involving the usage of animals were approved by the Animal Care and Use Committee of the University of Eastern Finland (license EKS-004-2014) and by the National Animal Experiment Board (ESAVI-2017-008787).

\subsection{Hemiskull preparation for ex vivo experiments}

For the in vitro and ex vivo experiments (mast cell staining, CGRP release assay, cytokine release assay, and electrophysiology), we used hemiskull preparations with preserved meninges and meningeal trigeminal innervation (Shatillo et al., 2013; Zakharov et al., 2015). For electrophysiology and CGRP release assay, animals we sacrificed with CO2 without anaesthesia. For cytokine release assay and mast cell staining, animals were anesthetized with intraperitoneal injection of $250 \mathrm{mg} / \mathrm{kg}$ tribromoethanol (Avertin, Sigma-Aldrich, USA) and then underwent transcardial perfusion: for mast cell staining, we perfused with normal saline (6 minutes at $6 \mathrm{ml} / \mathrm{min}$ ), followed by $4 \%$ paraformaldehyde (PFA) (20 minutes at $3 \mathrm{ml} / \mathrm{min}$ ); for cytokine release assay, animals were just perfused with normal saline (4 min at $20 \mathrm{ml} / \mathrm{min}$ ). In order to prepare the hemiskulls for subsequent analyses, after decapitation, skin, muscles, and connective tissues, as well as brain were removed with particular care to not touch and damage the meninges. Thereafter, hemiskulls were isolated by cutting the skull along the sagittal axis (i.e., two hemiskulls were prepared from each animal).

\subsection{Mast cell staining}




\section{Meningeal lymphatics in migraine}

96 Hemiskulls of WT and K14 animals were prepared as described above, washed three times for

97

20 minutes in PBS (phosphate buffered saline), and stained for 60 minutes with $0.1 \%$ toluidine blue. Stained meninges were immediately imaged, using a Zeiss Axio Zoom.V16 stereomicroscope (Carl Zeiss AG, Germany), at 30x magnification. We imaged two identical regions-of-interest (ROIs) from each hemiskull: one including the superior sagittal sinus (SSS; at the border of the image) and the adjoining one, partially overlapping (approximately $10 \%$ of area) with the previous ROI. Size of each ROI was $3.7 \times 2.4 \mathrm{~mm}^{2}$. In total, four images were acquired from each mouse. From each ROI, the number of stained mast cells was calculated using ImageJ 1.51v software (National Institute of Health, USA).

\subsection{CGRP release assay}

The CGRP release assay was conducted on hemiskulls of WT and K14 animals as previously described (Mikhailov et al., 2019). We used a CGRP enzyme immunoassay kit (EIA kit, SPIbio, France) to measure CGRP release from hemiskull preparations. The levels of CGRP were assessed under control and $\mathrm{KCl}$-treated conditions.

First, fresh hemiskull preparations from WT and K14 animals were perfused for 40 min with artificial cerebrospinal fluid (aCSF in mM: $119 \mathrm{NaCl}, 30 \mathrm{NaHCO}_{3}, 11$ glucose, $2.5 \mathrm{KCl}, 1$ $\mathrm{MgCl}_{2}, 1 \mathrm{NaH}_{2} \mathrm{PO}_{4}, 2 \mathrm{CaCl}_{2}$, adjusted $\mathrm{pH}$ level = 7.4) at room temperature (RT). Then, hemiskulls were washed four times with $150 \mu \mathrm{aCSF}$ for 15 minutes at $37^{\circ} \mathrm{C}$ to stabilize the basal condition. Samples of aCSF (100 $\mu$ l each) from the last two washes were collected to assess the basal level of CGRP (control conditions). After the last wash, hemiskulls were bathed with an aCSF solution containing $30 \mathrm{mM} \mathrm{KCl}$ for 15 minutes. Thereafter, a $100 \mu 1$ sample was collected to assess CGRP under KCl-treated condition.

Samples were freezed with liquid nitrogen in tubes containing EIA buffer with peptidase inhibitors. Assay protocol was carried out in accordance with instructions of manufacturer. In brief, $100 \mu \mathrm{l}$ of CGRP standard (for calibration curve) or sample were mixed with $100 \mu \mathrm{l}$ of anti-CGRP AChE tracer in a well plate, preliminary washed 5 times with washing buffer. After incubating the plates at $4{ }^{\circ} \mathrm{C}$ for $16-20 \mathrm{~h}$, supernatant was removed, and plates were washed 6 times with washing buffer. Finally, $200 \mu \mathrm{l}$ of Ellman's reagent was added. Optical density was measured at $405 \mathrm{~nm}$ using microplate reader (Wallac VICTOR2 ${ }^{\mathrm{TM}}$, PerkinElmer, USA).

\subsection{Cytokine release assay}

For cytokine release assay, we used hemiskull preparations from both WT and K14 mice. One hemiskull/animal was used to assess the release of cytokine under the control condition, while the contralateral was used to measure the release of cytokine under treatment condition (100 $\mu \mathrm{M}$ benzoyl ATP, BzATP). After the collection of hemiskulls, all procedures were performed at $37^{\circ} \mathrm{C}$. Hemiskulls were bathed in $150 \mu \mathrm{l}$ of either aCSF or aCSF + BzATP for three and a half hours. aCSF samples $(50 \mu \mathrm{l})$ were taken to assess the level of cytokines in control (treated with aCSF only) or stimulated (aCSF + BzATP) conditions. The more stable ATP-analogue 


\section{Meningeal lymphatics in migraine}

133 BzATP was used for the cytokine release assay, due to the long treatment time $\left(3 \frac{1}{2} \mathrm{~h}\right)$ and

134 because of fast degradation of ATP (Yegutkin et al., 2016). The levels of aCSF in the 135 hemiskulls were monitored throughout the incubation period. If needed, we refilled the 136 hemiskull preparation with the respective treatment solution to compensate for evaporation.

137 To assess the level of cytokines (IL-6, IL-10, MCP-1, TNF $\alpha$, IFN $\gamma$, IL-12p70), we used the 138 CBA Mouse Inflammation Kit (Cytometric Bead Array, BD Biosciences, New Jersey, USA). 139 All procedures (sample and standard beads preparation) were performed following instructions 140 provided by the manufacturer. Data were acquired on the CytoFLEX S cytometer (Beckman 141 Coulter Inc., USA) and analyzed with the Flow Cytometric Analysis Program (FCAP) Array 142 software (BD Biosciences, USA).

143 Due to the low concentration of IL-12p70 and IFN $\gamma$, in some samples it was not possible to 144 quantify the exact concentration with the abovementioned method. Thus, for these cytokines 145 final $n$ was lower than the total number of animals used for the assay.

\section{$146 \quad 2.6 \quad$ Electrophysiology}

147 Direct recording of action potentials from the trigeminal nerve afferents innervating meninges 148 was conducted as described earlier (Shatillo et al., 2013; Zakharov et al., 2015). Briefly, 149 hemiskulls of WT and K14 animals were placed in a perfusion chamber with a constant flow $150(6 \mathrm{ml} / \mathrm{min})$ of oxygenated aCSF. In order to access the nervus spinosus of the trigeminal nerve, 151 innervating meninges, we made a small incision in the dura mater. Next, the nervus spinosus 152 was sucked into a glass recording electrode filled with aCSF. We recorded 10 min of 153 spontaneous activity to get a baseline and to assess the difference in basal activity between WT 154 and K14 animals. Then, we applied $100 \mu \mathrm{M}$ ATP for $10 \mathrm{~min}$ to stimulate nociceptive firing in the trigeminal nerve (Zakharov et al., 2016), followed by $10 \mathrm{~min}$ of washout. The recording

156 was conducted with a digital amplifier (ISO 80, WPI Inc., USA) with bandpass $300 \mathrm{~Hz}-3$ $157 \mathrm{kHz}$, gain 10000. Signals were digitized at $125 \mathrm{kHz}$ using a NIPCI 6221 data acquisition board 158 (National Instruments, USA) and visualized with WinEDR software (Strathclyde University, 159 UK).

\subsection{Meningeal nerve staining for $\beta$-tubulin III}

161 For the meningeal nerve staining, meninges from PFA-fixed hemiskulls were isolated as 162 previously described (Louveau et al., 2015), and stained. Briefly, meningeal whole-mount 163 preparations were incubated with 1x phosphate-buffered saline (PBS) containing 2\% normal 164 goat serum (NGS), $1 \%$ bovine serum albumin (BSA), $0.1 \%$ Triton $\mathrm{X}-100$, and $0.05 \%$ Tween 16520 for 1 hour at RT. After that, meninges were incubated with rabbit anti- $\beta$-tubulin III (1:1000, 166 Cat\# T2200, Sigma-Aldrich, USA) overnight at $4^{\circ} \mathrm{C}$ in PBS containing $1 \%$ BSA and $0.5 \%$ 167 Triton X-100. Whole-mounts were washed in PBS at RT (3x) followed by incubation with 168 Alexa Fluor 488-conjugated goat anti-rabbit IgG antibody (1:500, Cat\# A11008, Invitrogen, 169 USA) for 1 hour at RT in PBS with $1 \%$ BSA and $0.5 \%$ Triton X-100. After further washing in 


\section{Meningeal lymphatics in migraine}

170 PBS (3x) and in phosphate buffer (PB; 2x), meninges were mounted with VECTASHIELD

171 mounting medium (Vector Laboratories, USA), including DAPI, and coverslipped.

172 Images were acquired using a Leica TCS SP8 X confocal system (Leica Microsystems,

173 Germany) using the LAS X software. Images of the region of interest, adjacent to the middle

174 meningeal artery, were acquired with a 20x objective with 0.75 numerical aperture (NA), with

175 an in-plane pixel size of $1.14 \times 1.14 \mu \mathrm{m}^{2}$ and a $\mathrm{z}$-step of $1 \mu \mathrm{m}$. The full images were created by

176 merging $4 \times 4$ tile scans, covering a total area of $2034 \times 2034 \mu \mathrm{m}^{2}$.

\section{$177 \quad 2.8 \quad$ Axon segmentation and innervation analysis}

178 We developed a semi-automated segmentation technique to annotate axons and analyze the innervation in acquired 3D confocal microscopy images. An experienced researcher (AA)

180 inserts two points along the desired axon on the $2 \mathrm{D}$ maximum projection of a $3 \mathrm{D}$ confocal 181 image to define the axonal centerline. Given the two points, a minimal path algorithm 182 (Benmansour and Cohen, 2011) detects the centerline of that axon. We used active contours 183 (Chan and Vese, 2001) to segment the desired axon, initiating from the detected axonal 184 centerline. For each axon, we measured the axonal diameter and the length of the centerlines

185

186 in 3D (Abdollahzadeh et al., 2019a). We also quantified an innervation complexity value for each meningeal tissue by forming a graph from the segmented axons (Abdollahzadeh et al., $2019 b$ ) and reported the number of axonal endpoints, as shown in Fig.7a. We described the details of axon segmentation and the morphology analysis in Supplementary Materials ("axon segmentation and innervation analysis" section).

\subsection{Statistical analysis}

We performed statistical analysis using the GraphPad Prism 8.4.2 software (GraphPad Software, California, USA). The data are presented as mean \pm the standard error of the mean (for two-way ANOVA) or as median with interquartile range (for Mann-Whitney U test and linear mixed effect model). We set the alpha-threshold defining the statistical significance as 0.05 for all analyses. Mast cell abundance as well as axon segmentation and innervation analyses data were analysed using Mann-Whitney U test. CGRP release assay data was analysed with repeated measures two-way ANOVA. Cytokine release assay data were analysed by Mann-Whitney U test or by matched two-way ANOVA. A linear mixed effect model was used to evaluate the differences in the electrophysiology data. Bonferroni correction was used to adjust p-values in multiple comparison. Please see figure legends for the details of the used test in each analysis.

\section{Results}

\subsection{Elevated number of mast cells in meninges of mice without lymphatic system}




\section{Meningeal lymphatics in migraine}

204 Meningeal mast cells recently emerged as important players in the initiation of a migraine

205 attack (Giniatullin et al., 2019; Kilinc et al., 2017; Koyuncu Irmak et al., 2019; Levy, 2009).

206 As the mLVs are important for the movement of immune cells (Ahn et al., 2019; Louveau et

207 al., 2015), we expected that the lack of mLVs could affect the local accumulation of mast cells.

208 We used the toluidine blue labelling to characterize the profile of meningeal mast cells.

209 In WT animals a substantial portion of mast cells was located along the meningeal blood 210 vessels (Figure 2A), where the mLVs are located (Antila et al., 2017; Aspelund et al., 2015).

211 A similar pattern of mast cell positioning was observed in K14 animals (Figure 2B). K14 212 animals showed a non-significant trend towards increased number of meningeal mast cells

213 (Figure 2.C). Since an increase in the number of mast cells may lead to a more abundant release 214 of local mediators (Giniatullin et al., 2019; Levy, 2009; Suleimanova et al., 2020), resulting in 215 meningeal inflammation and in the stimulation of the trigeminal afferents (Kilinc et al., 2017;

216 Koroleva et al., 2019), we analyzed the levels of the different migraine-associated pro217 inflammatory molecules and the activation of the trigeminal nerves in the K14 and their WT 218 littermates mice.

\section{$219 \quad 3.2 \quad$ Altered cytokine release in meninges}

220 We first measured the level of cytokines (IL-6, IL-10, IL-12p70, MCP-1, TNF $\alpha$, and IFN $\gamma$ ) 221 released into meninges in basal conditions (Figure 3). The level of the pro-inflammatory MCP2221 was significantly higher in K14 animals compared to their WT controls (Figure 3C). On the contrary, the basal level of IL-12p70 (also a pro-inflammatory cytokine) was significantly decreased in K14 animals compared to WT littermates (Figure 3E). No differences in the levels of all the other measured cytokines were observed in basal conditions between the two genotypes (Figure 3).

227 To mimic inflammatory conditions in the meanings, we used BzATP, a stable ATP analogue 228 (Baraldi et al., 2005), to stimulate the pro-inflammatory P2X7 receptors (Takenaka et al., 2016) 229 in the dural immune cells, including mast cells (Nurkhametova et al., 2019). Then, we 230 measured the cytokine release from meninges of both WT and K14 animals. Stimulation with $231100 \mu \mathrm{M}$ BzATP significantly increased the levels of $\mathrm{IL}-10$ and TNFa (Figure 4B, D). 232 Interestingly, while the IL-10 increase did not differ between the WT and K14 mice, BzATP-

233 stimulated release of the pro-inflammatory cytokine $\mathrm{TNF} \alpha$ was significant exclusively in the 234 WT genotype (Figure 4D). BzATP stimulation did not alter the levels of other measured 235 cytokines.

\section{$236 \quad 3.3$ Decreased CGRP release in meninges of mice lacking lymphatic system}

237 Next, we measured the level of CGRP released in meninges in both basal and stimulated 238 conditions (Figure 5). Basal CGRP levels, as measured in two consecutive samples (baselines, 


\section{Meningeal lymphatics in migraine}

239 BL), were similar in both genotypes. Interestingly, stimulation with $30 \mathrm{mM} \mathrm{KCl}$, which leads

240 to CGRP release through the stimulation of peptidergic nerve fibers, induced a significantly

241 lower increase of CGRP levels in K14 compared to WT hemiskulls (Figure 5A).

242

243

244

245

246

247

248

249

250

251

252

253

254

255

256

257

258

259

260

261

262

263

264

265

266

267

268

269

270

271

272

\subsection{Spontaneous and ATP-induced spiking activity in meningeal nerves of mice} lacking meningeal lymphatic system

To address the state of trigeminal nociception in animals without the lymphatic system, we recorded spiking activity from meningeal afferents. First, we recorded spiking activity in trigeminal nerve fibers in hemiskulls under basal conditions. Thereafter, we stimulated nerve terminals with ATP, a powerful trigger of local nociception (Koroleva et al., 2019; Yegutkin et al., 2016) (Figure 6A). In both genotypes, we observed a comparable increase in the nociceptive-related firing after ATP stimulation (Figure 6B).

\subsection{Unchanged patterns of meningeal innervation}

To evaluate the density of trigeminal innervation in hemiskull preparations from WT and K14 animals we stained meningeal preparations with the antibodies specific to the neuronal marker $\beta$-tubulin III (Figure 7) (Cáceres et al., 1986). After that, we applied a semi-automated segmentation method to evaluate the following parameters: total innervation length (indirect evaluation of the innervation density in the meninges) and number of terminal points (i.e., trigeminal fiber terminal endings, likely releasing CGRP). None of the analyzed parameters showed a difference between the genotypes.

\section{Discussion}

Our study evaluated the role of the meningeal lymphatic system in the regulation of the neurochemical profile and functional properties of the meningeal trigeminovascular system (TVS), implicated in migraine pain. In K14 mice, lacking mLVs, we found that the stimulated release of CGRP, as well as the release of pro-inflammatory IL-12p70 and TNF $\alpha$ were decreased. On the contrary, we observed an increase in the levels of the pro-inflammatory cytokine MCP-1. The density of trigeminal meningeal innervation and nociceptive activity of nerve terminals were not altered in animals lacking meningeal lymphatic system. The main findings are summarized in Figure 8.

\subsection{Dural inflammation responding to the deficiency of the lymphatic system}

Meninges represent the main site for the generation of migraine pain (Messlinger, 2009; Pietrobon and Moskowitz, 2013). This brain surrounding membranes comprise blood vessels, sensory nerve fibers and a high diversity of local immune cells (McIlvried et al., 2017; Olesen et al., 2009; Pietrobon and Moskowitz, 2013). Among the latter, lymphocytes and mast cells have been reported to be present in high amount dura mater membranes (McIlvried et al., 


\section{Meningeal lymphatics in migraine}

273 2017). In migraine-like conditions, meninges are involved in so-called 'neurogenic

274 inflammation', which is induced and maintained by neuropeptides, such as CGRP, released

275

276

277

278

279

280

281

282

283

284

285

286

287

288

289

290

291

292

293

294

295

296

297

298

299

300

301

302

303

304

305

306

307

308

309

310

311 from trigeminal nerve fibers (Eftekhari et al., 2013; Mason et al., 1984). CGRP is currently recognized as one of the central migraine mediator, with multiple targets including dural vessels (Goadsby et al., 1988), meningeal nerve fibers (Cady et al., 2011) and immune cells (Ottosson and Edvinsson, 1997). Interestingly, it was proposed, that impaired clearance of CGRP from perivascular space can be a reason for post-traumatic headache after TBI (Piantino et al., 2019). Surprisingly, here we demonstrate that the release of CGRP in the meninges from K14 mice lacking mLVs is lower compared to WT control group, suggesting that K14 animals are less prone to trigger migraine attacks via this signalling pathway. . Noteworthy, CGRP is vital for lymphatic capillary formation (in particular, alleviating the severity of postoperative lymphedema) (Matsui et al., 2019), suggesting a potential positive crosstalk between CGRP signalling and activity of the meningeal lymphatic system. As local trigeminal nerve fibers are the main source of meningeal CGRP (Eftekhari et al., 2013; Mason et al., 1984), we proposed that the lymphatic impairment causes either a reduced storage of CGRP in trigeminal nerve terminals or lowered meningeal innervation by 'peptidergic' nerve fibers (Keller and Marfurt, 1991).

Previous studies on patients have mainly focused on cytokine profiling in the systemic circulation (Fidan et al., 2006; Khaiboullina et al., 2017; Oliveira et al., 2017; Perini et al., 2005; Sarchielli et al., 2004; Yücel et al., 2016), whereas the production of cytokines in the meninges have not been fully characterized. Various immune cells can be identified in the meninges, including cells transported within the mLVs (McIlvried et al., 2017; Alitalo, 2011; Hayday et al., 2001). These cells constitute the primary and major source of multiple proinflammatory and anti-inflammatory cytokines. Here we demonstrate that in the meninges the levels of IL-6, IL-10, MCP-1, TNF $\alpha$, IL-12p70, and IFN $\gamma$ are detectable already at basal conditions. In particular, we found the presence of the pro-inflammatory cytokines TNF $\alpha$ and IL-6, known to be associated with migraine pathology (Bø et al., 2009; Khaiboullina et al., 2017; Perini et al., 2005; Sarchielli et al., 2006; Wang et al., 2015; Yücel et al., 2016). Notably, the level of IL-6 was exceptionally high but did not differ between the two genotypes. However, we found that the absence of functional mLVs was associated with the increased levels of the pro-inflammatory cytokine MCP-1 (Wood et al., 2014). MCP-1 is known as the activator of mast cells, provoking release of mast cells derived components (Lv et al., 2012). In addition, MCP-1 delays mast cell death (Lopes et al., 2019). This supports our finding of higher number of mast cells in meninges lacking mLVs. Notably, an increase in MCP-1 was reported in the cerebrospinal fluid of patients during a migraine attack (Bø et al., 2009). In contrast, the levels of the pro-inflammatory cytokine (IL-12p70) (Martins et al., 2011), which is typically released from macrophages and dendritic cells (Müller-Berghaus et al., 2004), were reduced in the meninges from K14 animals lacking mLVs. It has been shown that IL12-p70 plasma level was increased in migraine patients during the interictal phase (Oliveira et al., 


\section{Meningeal lymphatics in migraine}

312 2017). The reduction of IL12-p70 in K14 animals lacking mLVs probably suggests a decreased

313 inflammatory state in the meninges. Notably, mast cells can release IL12-p70 (Mukai et al., 314 2018) in response to CGRP-induced degranulation (Ottosson and Edvinsson, 1997;

315 Theoharides et al., 2005). Our data showing decreased levels of CGRP in animals lacking 316 mLVs may imply that the absence of a functional meningeal lymphatic system leads to a 317 reduced tendency to develop a migraine through several downstream mechanisms controlled 318 by this neuropeptide.

319 Extracellular ATP, acting primarily via P2X7 receptors, is a powerful trigger of inflammatory 320 reactions involving different dural immune cells, including mast cells (Burnstock, 2016; 321 Karmakar et al., 2016; Nurkhametova et al., 2019, 2018). Consistent with this view, we found 322 that the stimulation of meninges with the P2X7 agonist BzATP stimulated the release of the 323 pro-inflammatory $\mathrm{TNF} \alpha$, a promoter of trigeminal pain (Franceschini et al., 2013). Notably,

324 ATP receptor stimulation resulted in the significant release of TNF $\alpha$ only in the meninges from 325 WT animals, but not in the meninges lacking the mLVs. TNF $\alpha$ is the main migraine-related 326 cytokine (Martami et al., 2018; Oliveira et al., 2017; Perini et al., 2005; Yücel et al., 2016). In 327 line with this, TNF $\alpha$ has been reported as the agent, which can stimulate CGRP transcription 328 (Bowen et al., 2006). Thus, the lack of increase in TNF $\alpha$ levels after ATP receptor stimulation 329 is consistent with our other findings on the reduced level of CGRP in the K14 animals. Taken 330 together, the lack of meningeal lymphatic system may induce a local shift in the balance of 331 various humoral factors (i.e., CGRP and pro-inflammatory cytokines such as TNF $\alpha$ ), 332 suggesting a reduction in the neurogenic inflammation signalling.

\section{$333 \quad 4.2$ Meningeal nociception and morphological properties of nerve terminals}

334 ATP is a powerful trigger of meningeal nociception (Koroleva et al., 2019; Yegutkin et al., 335 2016). Notably, ATP can operate either directly via neuronal P2X3 receptors (Yegutkin et al., 336 2016), or by degranulating mast cells and release of serotonin, which acts via 5-HT3 receptors 337 at meningeal nerve terminals (Koroleva et al., 2019). However, despite elevated mast cell levels 338 found in K14 mice, these mechanisms do not lead to significant differences in spiking activity 339 between the two genotypes.

340 Since CGRP is released by trigeminal afferents, we tested if the diminished CGRP release, 341 observed in K14 meninges, resulted from the reduced density of trigeminal innervation of dura 342 mater. To investigate this hypothesis, we analyzed several parameters of meningeal 343 innervation. Meningeal sensory nerve fibers are characterized mainly by nociceptive A $\delta$ and 344 peptidergic C-fibers (Levy and Strassman, 2002), with the latter considered as the primary 345 source of CGRP (Eftekhari et al., 2013). Analysis of total length of axonal fibers and of the 346 number of terminal segments of meningeal afferents in the meninges of K14 mice did not show 347 any difference compared to WT littermates. This suggests that the lower CGRP released in 348 K14 mice is not affected by an altered density of meningeal innervation, but rather represents 


\section{Meningeal lymphatics in migraine}

349 the different content of neuropeptides or a reduced functionality of the CGRP releasing

350 machinery.

351 In conclusion, our data show that innate deficiency in the meningeal lymphatics (as observed

352 in the K14 mice used in this study) results in the alteration of pro-inflammatory signals in the

353 meninges, including the increased recruitment of mast cells and, on the other side, a decrease

354 in the levels of the principal migraine-associated pro-inflammatory cytokines. This novel

355 phenotype suggests the presence of modulatory (compensatory) mechanisms aimed at

356 balancing the local inflammation in the meninges and limit the triggering of nociceptive

357 signals.

\subsection{Limitations of the model}

359 To the best of our knowledge, this is the first study investigating the interactions between the 360 meningeal lymphatic system, neurogenic inflammation and nociception, which can contribute 361 to generation of migraine pain. However, the model used in our study has some limitations. 362 First, all our experiments have been conducted in ex vivo conditions. In this preparation, the 363 meningeal lymphatic system is not active, thus affecting the recruitment and trafficking of 364 immune cells and clearance of migraine mediators. Second, our animals were not sensitized to 365 mimic migraine attacks. Third, only ATP (although one of most powerful algogen) was tested 366 as a trigger of the nociceptive response. Forth, it has been previously reported that K14 mice 367 present alterations in both systemic (Thomas et al., 2012) and neuro-immunity 368 (Wojciechowski et al., 2019), which involves mainly the T lymphocytes, which is only a subset 369 of immune cells known to be involved in migraine (Nurkhametova et al., 2018).

370 Therefore, in future studies, our results needs to be confirmed in in vivo migraine models (e.g., 371 nitroglycerin injection or CSD induction) (Demartini et al., 2019; Van Den Maagdenberg et 372 al., 2004) to better understand the impact of the meningeal lymphatic system on migraine state.

\section{$373 \quad 4.4$ Pathophysiological implications}

374 Here we explored a possible contribution of mLVs in migraine pathology, given the generally 375 accepted central role of the meningeal tissues in this disorder. Our main working hypothesis was that the lack of functional meningeal lymphatic system would affect the clearance of the dural environment, resulting in the exaggeration of neurogenic inflammation and nociception, and leading to more severe symptoms of migraine. Indeed, we found that the lack of the meningeal lymphatic is related to pro-nociceptive changes in the trigeminovascular system relevant to migraine pathology (i.e., enhanced expression of the pro-inflammatory cytokine MCP-1). However, we surprisingly also found that the expression of the key migraine mediator CGRP and of the pro-inflammatory cytokines TNF $\alpha$ and IL-12p70 was decreased. This suggest that the absence of mLVs caused not uniform, but rather more complex and eventually functionally opposite, changes in the inflammatory and nociceptive mechanisms in the meninges. Thus, the lack of mLVs, without specific promoters 


\section{Meningeal lymphatics in migraine}

386 of activated genetic factors, is not per se the main cause of migraine state, likely due to the

387 presence of the compensatory mechanisms primerely aimed at balance the local inflammation.

\section{Conflict of Interest}

390 None of the authors has any conflict of interest to disclose. The authors confirm that have read 391 the Journal's position on issues involved in ethical publication and affirm that this report is 392 consistent with those guidelines.

\section{Author Contributions}

394 NM, FMN and RashidG originally conceived the study; NM, FMN, RashidG elaborated the 395 study design; NM, KK, RaisaG performed experiments; NM, AA, OG, AS, JT analyzed the 396 data; NM, AA, OG, JT performed the statistical analysis; NM, FMN, AA, AS, FNM, RashidG 397 drafted a significant portion of the manuscript and figures. TM supported the study and edited 398 the manuscript. All authors contributed to manuscript revision, read, and approved the 399 submitted version.

\section{$\begin{array}{lll}400 & 7 & \text { Funding }\end{array}$}

401 This study has been supported by the Academy of Finland (Grant 325392 for NM, RG, 402 RashidG; Research Fellowship 309479/2017 for FMN) and by the Doctoral Program in 403 Molecular Medicine of University of Eastern Finland (for NM).

\section{Acknowledgements}

405 For help with cytokine release assay, we would like to thank Sara Wojciechowski, Dilyara 406 Nurkhametova and Sanna Loppi. For meningeal immunostaining, we would like to thank Maria 407 Vihma.

4089 Data Availability

409 The raw data supporting the conclusions of this manuscript will be made available by the 410 corresponding author, upon reasonable request, to any qualified researcher. 


\section{Meningeal lymphatics in migraine}

\section{References}

Abdollahzadeh, A., Belevich, I., Jokitalo, E., Tohka, J., Sierra, A., 2019a. Automated 3D Axonal Morphometry of White Matter. Sci. Rep. 9, 1-16. https://doi.org/10.1038/s41598-019-42648-2

Abdollahzadeh, A., Sierra, A., Tohka, J., 2019b. Cylindrical shape decomposition for 3D segmentation of tubular objects. arXiv:1911.00571v2.

Ahn, J.H., Cho, H., Kim, J.H., Kim, S.H., Ham, J.S., Park, I., Suh, S.H., Hong, S.P., Song, J.H., Hong, Y.K., Jeong, Y., Park, S.H., Koh, G.Y., 2019. Meningeal lymphatic vessels at the skull base drain cerebrospinal fluid. Nature 572, 62-66. https://doi.org/10.1038/s41586-019-1419-5

Alitalo, K., 2011. The lymphatic vasculature in disease. Nat. Med. https://doi.org/10.1038/nm.2545

Antila, S., Karaman, S., Nurmi, H., Airavaara, M., Voutilainen, M.H., Mathivet, T., Chilov, D., Li, Z., Koppinen, T., Park, J.H., Fang, S., Aspelund, A., Saarma, M., Eichmann, A., Thomas, J.L., Alitalo, K., 2017. Development and plasticity of meningeal lymphatic vessels. J. Exp. Med. 214, 3645-3667. https://doi.org/10.1084/jem.20170391

Aspelund, A., Antila, S., Proulx, S.T., Karlsen, T.V., Karaman, S., Detmar, M., Wiig, H., Alitalo, K., 2015. A dural lymphatic vascular system that drains brain interstitial fluid and macromolecules. J. Exp. Med. 212, 991-9. https://doi.org/10.1084/jem.20142290

Baraldi, P., Virgilio, F., Romagnoli, R., 2005. Agonists and Antagonists Acting at P2X7 Receptor. Curr. Top. Med. Chem. 4, 1707-1717. https://doi.org/10.2174/1568026043387223

Benmansour, F., Cohen, L.D., 2011. Tubular structure segmentation based on minimal path method and anisotropic enhancement. Int. J. Comput. Vis. 92, 192-210. https://doi.org/10.1007/s11263-010-0331-0

Bø, S.H., Davidsen, E.M., Gulbrandsen, P., Dietrichs, E., Bovim, G., Stovner, L.J., White, L.R., 2009. Cerebrospinal fluid cytokine levels in migraine, tension-type headache and cervicogenic headache. Cephalalgia 29, 365-372. https://doi.org/10.1111/j.14682982.2008.01727.x

Bolay, H., Reuter, U., Dunn, A.K., Huang, Z., Boas, D.A., Moskowitz, M.A., 2002. Intrinsic brain activity triggers trigeminal meningeal afferents in a migraine model. Nat. Med. 8, 136-142. https://doi.org/10.1038/nm0202-136 


\section{Meningeal lymphatics in migraine}

Bowen, E.J., Schmidt, T.W., Firm, C.S., Russo, A.F., Durham, P.L., 2006. Tumor necrosis factor- $\alpha$ stimulation of calcitonin gene-related peptide expression and secretion from rat trigeminal ganglion neurons. J. Neurochem. 96, 65-77. https://doi.org/10.1111/j.14714159.2005.03524.x

Burnstock, G., 2016. P2X ion channel receptors and inflammation. Purinergic Signal. 12, 5967. https://doi.org/10.1007/s11302-015-9493-0

Cáceres, A., Banker, G.A., Binder, L., 1986. Immunocytochemical localization of tubulin and microtubule-associated protein 2 during the development of hippocampal neurons in culture. J. Neurosci. 6, 714-22.

Cady, R.J., Glenn, J.R., Smith, K.M., Durham, P.L., 2011. Calcitonin gene-related peptide promotes cellular changes in trigeminal neurons and glia implicated in peripheral and central sensitization. Mol. Pain 7, 94. https://doi.org/10.1186/1744-8069-7-94

Chan, T.F., Vese, L.A., 2001. Active contours without edges. IEEE Trans. Image Process. 10, 266-277. https://doi.org/10.1109/83.902291

Delépine, L., Aubineau, P., 1997. Plasma Protein Extravasation Induced in the Rat Dura Mater by Stimulation of the Parasympathetic Sphenopalatine Ganglion. Exp. Neurol. 147, 389-400. https://doi.org/10.1006/exnr.1997.6614

Demartini, C., Greco, R., Zanaboni, A.M., Sances, G., De Icco, R., Borsook, D., Tassorelli, C., 2019. Nitroglycerin as a comparative experimental model of migraine pain: From animal to human and back. Prog. Neurobiol. https://doi.org/10.1016/j.pneurobio.2019.02.002

Ebersberger, A., Takac, H., Richter, F., Schaible, H.-G., 2006. Effect of sympathetic and parasympathetic mediators on the release of calcitonin gene-related peptide and prostaglandin E from rat dura mater, in vitro. Cephalalgia 26, 282-289. https://doi.org/10.1111/j.1468-2982.2005.01035.x

Eftekhari, S., Warfvinge, K., Blixt, F.W., Edvinsson, L., 2013. Differentiation of nerve fibers storing CGRP and CGRP receptors in the peripheral trigeminovascular system. J. Pain 14, 1289-1303. https://doi.org/10.1016/j.jpain.2013.03.010

Fidan, I., Yüksel, S., Ýmir, T., Irkeç, C., Aksakal, F.N., 2006. The importance of cytokines, chemokines and nitric oxide in pathophysiology of migraine. J. Neuroimmunol. 171, 184-188. https://doi.org/10.1016/j.jneuroim.2005.10.005

Franceschini, A., Vilotti, S., Ferrari, M.D., van den Maagdenberg, A.M.J.M., Nistri, A., 


\section{Meningeal lymphatics in migraine}

Fabbretti, E., 2013. TNFa Levels and Macrophages Expression Reflect an Inflammatory Potential of Trigeminal Ganglia in a Mouse Model of Familial Hemiplegic Migraine. PLoS One 8, e52394. https://doi.org/10.1371/journal.pone.0052394

Giniatullin, R., Gupta, K., Theoharides, T., 2019. Editorial: Mast Cells in Itch, Pain and Neuro-Inflammation. Front. Cell. Neurosci. 13, 521. https://doi.org/10.3389/fncel.2019.00521

Giniatullin, R., Nistri, A., Fabbretti, E., 2008. Molecular mechanisms of sensitization of paintransducing P2X3 receptors by the migraine mediators CGRP and NGF. Mol. Neurobiol. https://doi.org/10.1007/s12035-008-8020-5

Goadsby, P.J., Edvinsson, L., Ekman, R., 1988. Release of vasoactive peptides in the extracerebral circulation of humans and the cat during activation of the trigeminovascular system. Ann. Neurol. 23, 193-196. https://doi.org/10.1002/ana.410230214

Hayday, A., Theodoridis, E., Ramsburg, E., Shires, J., 2001. Intraepithelial lymphocytes: Exploring the Third Way in immunology. Nat. Immunol. https://doi.org/10.1038/ni1101997

Karmakar, M., Katsnelson, M.A., Dubyak, G.R., Pearlman, E., 2016. Neutrophil P2X7 receptors mediate NLRP3 inflammasome-dependent $\mathrm{IL}-1 \beta$ secretion in response to ATP. Nat. Commun. 7, 10555. https://doi.org/10.1038/ncomms 10555

Keller, J.T., Marfurt, C.F., 1991. Peptidergic and serotoninergic innervation of the rat dura mater. J. Comp. Neurol. 309, 515-534. https://doi.org/10.1002/cne.903090408

Khaiboullina, S.F., Mendelevich, E.G., Shigapova, L.H., Shagimardanova, E., Gazizova, G., Nikitin, A., Martynova, E., Davidyuk, Y.N., Bogdanov, E.I., Gusev, O., Van Den Maagdenberg, A.M.J.M., Giniatullin, R.A., Rizvanov, A.A., 2017. Cerebellar atrophy and changes in cytokines associated with the CACNA1A R583Q mutation in a Russian familial hemiplegic migraine type 1 family. Front. Cell. Neurosci. 11, 263. https://doi.org/10.3389/fncel.2017.00263

Kilinc, E., Guerrero-Toro, C., Zakharov, A., Vitale, C., Gubert-Olive, M., Koroleva, K., Timonina, A., Luz, L.L., Shelukhina, I., Giniatullina, R., Tore, F., Safronov, B. V., Giniatullin, R., 2017. Serotonergic mechanisms of trigeminal meningeal nociception: Implications for migraine pain. Neuropharmacology 116, 160-173. https://doi.org/10.1016/j.neuropharm.2016.12.024 


\section{Meningeal lymphatics in migraine}

G., Mattila, O.S., Lindsberg, P.J., Malm, T.M., Giniatullin, R., 2019. Meningeal mast cells contribute to ATP-induced nociceptive firing in trigeminal nerve terminals: Direct and indirect purinergic mechanisms triggering migraine pain. Front. Cell. Neurosci. 13. https://doi.org/10.3389/fncel.2019.00195

Koyuncu Irmak, D., Kilinc, E., Tore, F., 2019. Shared fate of meningeal mast cells and sensory neurons in migraine. Front. Cell. Neurosci. 13. https://doi.org/10.3389/fncel.2019.00136

Kwon, S., Moreno-Gonzalez, I., Taylor-Presse, K., Edwards, G., Gamez, N., Calderon, O., Zhu, B., Velasquez, F.C., Soto, C., Sevick-Muraca, E.M., 2019. Impaired Peripheral Lymphatic Function and Cerebrospinal Fluid Outflow in a Mouse Model of Alzheimer's Disease. J. Alzheimer's Dis. 69, 585-593. https://doi.org/10.3233/JAD-190013

Levy, D., 2009. Migraine pain, meningeal inflammation, and mast cells. Curr. Pain Headache Rep. 13, 237-40.

Levy, D., Strassman, A.M., 2002. Mechanical response properties of A and C primary afferent neurons innervating the rat intracranial dura. J Neurophysiol 88, 3021-3031. https://doi.org/10.1152/jn.00029.2002

Loberg, R.D., Day, L.S.L., Harwood, J., Ying, C., St. John, L.N., Giles, R., Neeley, C.K., Pienta, K.J., 2006. CCL2 is a potent regulator of prostate cancer cell migration and proliferation. Neoplasia 8, 578-586. https://doi.org/10.1593/neo.06280

Lopes, J.P., Stylianou, M., Backman, E., Holmberg, S., Ekoff, M., Nilsson, G., Urban, C.F., 2019. Cryptococcus neoformans Induces MCP-1 Release and Delays the Death of Human Mast Cells. Front. Cell. Infect. Microbiol. 9. https://doi.org/10.3389/fcimb.2019.00289

Louveau, A., Smirnov, I., Keyes, T.J., Eccles, J.D., Rouhani, S.J., Peske, J.D., Derecki, N.C., Castle, D., Mandell, J.W., Lee, K.S., Harris, T.H., Kipnis, J., 2015. Structural and functional features of central nervous system lymphatic vessels. Nature 523, 337-341. https://doi.org/10.1038/nature14432

Lv, J., Huang, Y., Zhu, S., Yang, G., Zhang, Y., Leng, J., Bo, J., Liu, D., 2012. MCP-1Induced Histamine Release from Mast Cells Is Associated with Development of Interstitial Cystitis/Bladder Pain Syndrome in Rat Models. Mediators Inflamm. 2012, 19. https://doi.org/10.1155/2012/358184

Mäkinen, T., Jussila, L., Veikkola, T., Karpanen, T., Kettunen, M.I., Pulkkanen, K.J., Kauppinen, R., Jackson, D.G., Kubo, H., Nishikawa, S.I., Ylä-Herttuala, S., Alitalo, K., 


\section{Meningeal lymphatics in migraine}

2001. Inhibition of lymphangiogenesis with resulting lymphedema in transgenic mice expressing soluble VEGF receptor-3. Nat. Med. 7, 199-205. https://doi.org/10.1038/84651

Martami, F., Razeghi Jahromi, S., Togha, M., Ghorbani, Z., Seifishahpar, M., Saidpour, A., 2018. The serum level of inflammatory markers in chronic and episodic migraine: a case-control study. Neurol. Sci. 39, 1741-1749. https://doi.org/10.1007/s10072-0183493-0

Martins, T.B., Rose, J.W., Jaskowski, T.D., Wilson, A.R., Husebye, D., Seraj, H.S., Hill, H.R., 2011. Analysis of proinflammatory and anti-inflammatory cytokine serum concentrations in patients with multiple sclerosis by using a multiplexed immunoassay. Am. J. Clin. Pathol. 136, 696-704. https://doi.org/10.1309/AJCP7UBK8IBVMVNR

Mason, R.T., Peterfreund, R.A., Sawchenko, P.E., Corrigan, A.Z., Rivier, J.E., Vale, W.W., 1984. Release of the predicted calcitonin gene-related peptide from cultured rat trigeminal ganglion cells. Nature 308, 653-5.

Matsui, S., Tanaka, M., Kamiyoshi, A., Sakurai, T., Ichikawa-Shindo, Y., Kawate, H., Dai, K., Cui, N., Wei, Y., Tanaka, M., Kakihara, S., Nakamura, K., Yamauchi, A., Ishida, K., Tanaka, S., Kawamata, M., Shindo, T., 2019. Endogenous Calcitonin Gene-Related Peptide Deficiency Exacerbates Postoperative Lymphedema by Suppressing Lymphatic Capillary Formation and M2 Macrophage Accumulation. Am. J. Pathol. 189, 24872502. https://doi.org/10.1016/j.ajpath.2019.08.011

McIlvried, L.A., Cruz, J.A., Borghesi, L.A., Gold, M.S., 2017. Sex-, stress-, and sympathetic post-ganglionic-dependent changes in identity and proportions of immune cells in the dura. Cephalalgia 37, 36-48. https://doi.org/10.1177/0333102416637832

Messlinger, K., 2009. Migraine: Where and how does the pain originate? Exp. Brain Res. 196, 179-193. https://doi.org/10.1007/s00221-009-1756-y

Mikhailov, N., Leskinen, J., Fagerlund, I., Poguzhelskaya, E., Giniatullina, R., Gafurov, O., Malm, T., Karjalainen, T., Gröhn, O., Giniatullin, R., 2019. Mechanosensitive meningeal nociception via Piezo channels: Implications for pulsatile pain in migraine?

Neuropharmacology 149, 113-123. https://doi.org/10.1016/J.NEUROPHARM.2019.02.015

Moskowitz, M.A., 1993. Neurogenic inflammation in the pathophysiology and treatment of migraine. Neurology 43, S16-S20.

Moskowitz, M.A., 1984. The neurobiology of vascular head pain. Ann. Neurol. 16, 157-168. 


\section{Meningeal lymphatics in migraine}

Moskowitz, M.A., Romero, J., Reinhard, J.F., Melamed, E., Pettibone, D.J., 1979. NEUROTRANSMITTERS AND THE FIFTH CRANIAL NERVE: IS THERE A RELATION TO THE HEADACHE PHASE OF MIGRAINE? Lancet 314, 883-885. https://doi.org/10.1016/S0140-6736(79)92692-8

Mukai, K., Tsai, M., Saito, H., Galli, S.J., 2018. Mast cells as sources of cytokines, chemokines, and growth factors. Immunol. Rev. https://doi.org/10.1111/imr.12634

Müller-Berghaus, J., Kern, K., Paschen, A., Nguyen, X.D., Klüter, H., Morahan, G., Schadendorf, D., 2004. Deficient IL-12p70 secretion by dendritic cells based on IL12B promoter genotype. Genes Immun. 5, 431-434. https://doi.org/10.1038/sj.gene.6364102

Noé, F.M., Marchi, N., 2019. Central nervous system lymphatic unit, immunity, and epilepsy: Is there a link? Epilepsia Open. https://doi.org/10.1002/epi4.12302

Nurkhametova, D., Kudryavtsev, I., Guselnikova, V., Serebryakova, M., Giniatullina, R.R., Wojciechowski, S., Tore, F., Rizvanov, A., Koistinaho, J., Malm, T., Giniatullin, R., 2019. Activation of $\mathrm{P} 2 \mathrm{X} 7$ receptors in peritoneal and meningeal mast cells detected by uptake of organic dyes: Possible purinergic triggers of neuroinflammation in meninges. Front. Cell. Neurosci. 13. https://doi.org/10.3389/fncel.2019.00045

Nurkhametova, D., Kudryavtsev, I., Khayrutdinova, O., Serebryakova, M., Altunbaev, R., Malm, T., Giniatullin, R., 2018. Purinergic profiling of regulatory T-cells in patients with episodic migraine. Front. Cell. Neurosci. 12. https://doi.org/10.3389/fncel.2018.00326

Olesen, J., Burstein, R., Ashina, M., Tfelt-Hansen, P., 2009. Origin of pain in migraine: evidence for peripheral sensitisation. Lancet Neurol. https://doi.org/10.1016/S14744422(09)70090-0

Oliveira, A.B., Bachi, A.L.L., Ribeiro, R.T., Mello, M.T., Tufik, S., Peres, M.F.P., 2017. Unbalanced plasma TNF- $\alpha$ and IL-12/IL-10 profile in women with migraine is associated with psychological and physiological outcomes. J. Neuroimmunol. 313, 138144. https://doi.org/10.1016/j.jneuroim.2017.09.008

Ottosson, A., Edvinsson, L., 1997. Release of histamine from dural mast cells by substance P and calcitonin gene-related peptide. Cephalalgia 17, 166-174. https://doi.org/10.1046/j.1468-2982.1997.1703166.x

Patel, T.K., Habimana-Griffin, L., Gao, X., Xu, B., Achilefu, S., Alitalo, K., McKee, C.A., 


\section{Meningeal lymphatics in migraine}

Sheehan, P.W., Musiek, E.S., Xiong, C., Coble, D., Holtzman, D.M., 2019. Dural lymphatics regulate clearance of extracellular tau from the CNS. Mol. Neurodegener. 14. https://doi.org/10.1186/s13024-019-0312-x

Perini, F., D’Andrea, G., Galloni, E., Pignatelli, F., Billo, G., Alba, S., Bussone, G., Toso, V., 2005. Plasma cytokine levels in migraineurs and controls. Headache 45, 926-931. https://doi.org/10.1111/j.1526-4610.2005.05135.x

Piantino, J., Lim, M.M., Newgard, C.D., Iliff, J., 2019. Linking Traumatic Brain Injury, Sleep Disruption and Post-Traumatic Headache: a Potential Role for Glymphatic Pathway Dysfunction. Curr. Pain Headache Rep. https://doi.org/10.1007/s11916-019-0799-4

Pietrobon, D., Moskowitz, M.A., 2013. Pathophysiology of Migraine. Annu. Rev. Physiol. 75, 365-391. https://doi.org/10.1146/annurev-physiol-030212-183717

Ramachandran, R., 2018. Neurogenic inflammation and its role in migraine. Semin. Immunopathol. 40, 301-314. https://doi.org/10.1007/s00281-018-0676-y

Rasmussen, M.K., Mestre, H., Nedergaard, M., 2018. The glymphatic pathway in neurological disorders. Lancet Neurol. https://doi.org/10.1016/S1474-4422(18)30318-1

Sarchielli, P., Alberti, A., Vaianella, L., Pierguidi, L., Floridi, A., Mazzotta, G., Floridi, A., Gallai, V., 2004. Chemokine levels in the jugular venous blood of migraine without aura patients during attacks. Headache 44, 961-968. https://doi.org/10.1111/j.15264610.2004.04189.x

Shatillo, A., Koroleva, K., Giniatullina, R., Naumenko, N., Slastnikova, A.A., Aliev, R.R., Bart, G., Atalay, M., Gu, C., Khazipov, R., Davletov, B., Grohn, O., Giniatullin, R., 2013. Cortical spreading depression induces oxidative stress in the trigeminal nociceptive system. Neuroscience 253, 341-349. https://doi.org/10.1016/j.neuroscience.2013.09.002

Shelukhina, I., Mikhailov, N., Abushik, P., Nurullin, L., Nikolsky, E.E., Giniatullin, R., 2017. Cholinergic Nociceptive Mechanisms in Rat Meninges and Trigeminal Ganglia: Potential Implications for Migraine Pain. Front. Neurol. 8, 163. https://doi.org/10.3389/fneur.2017.00163

Suleimanova, A., Talanov, M., Gafurov, O., Gafarov, F., Koroleva, K., Virenque, A., Noe, F.M., Mikhailov, N., Nistri, A., Giniatullin, R., 2020. Modeling a Nociceptive NeuroImmune Synapse Activated by ATP And 5-HT in Meninges: Novel Clues On Transduction of Chemical Signals into Persistent or Rhythmic Neuronal Firing. Front. Cell. Neurosci. 


\section{Meningeal lymphatics in migraine}

Takenaka, M.C., Robson, S., Quintana, F.J., 2016. Regulation of the T Cell Response by CD39. Trends Immunol. https://doi.org/10.1016/j.it.2016.04.009

Tamura, R., Yoshida, K., Toda, M., 2019. Current understanding of lymphatic vessels in the central nervous system. Neurosurg. Rev. https://doi.org/10.1007/s10143-019-01133-0

Theoharides, T.C., Donelan, J., Kandere-Grzybowska, K., Konstantinidou, A., 2005. The role of mast cells in migraine pathophysiology. Brain Res. Rev. https://doi.org/10.1016/j.brainresrev.2004.11.006

Thomas, S.N., Rutkowski, J.M., Pasquier, M., Kuan, E.L., Alitalo, K., Randolph, G.J., Swartz, M.A., 2012. Impaired Humoral Immunity and Tolerance in K14-VEGFR-3-Ig Mice That Lack Dermal Lymphatic Drainage . J. Immunol. 189, 2181-2190. https://doi.org/10.4049/jimmunol.1103545

Van Den Maagdenberg, A.M.J.M., Pietrobon, D., Pizzorusso, T., Kaja, S., Broos, L.A.M., Cesetti, T., Van De Ven, R.C.G., Tottene, A., Van Der Kaa, J., Plomp, J.J., Frants, R.R., Ferrari, M.D., 2004. A Cacnala knockin migraine mouse model with increased susceptibility to cortical spreading depression. Neuron 41, 701-710. https://doi.org/10.1016/S0896-6273(04)00085-6

Wojciechowski, S., Vihma, M., Galbardi, B., Keuters, M., Antila, S., Koistinaho, J., Noe, F., 2019. The CNS lymphatic system modulates the adaptive neuro-immune response in the perilesional cortex after brain trauma. bioRxiv 821645. https://doi.org/10.1101/821645

Wood, S., Jayaraman, V., Huelsmann, E.J., Bonish, B., Burgad, D., Sivaramakrishnan, G., Qin, S., DiPietro, L.A., Zloza, A., Zhang, C., Shafikhani, S.H., 2014. Pro-inflammatory chemokine CCL2 (MCP-1) promotes healing in diabetic wounds by restoring the macrophage response. PLoS One 9, e91574. https://doi.org/10.1371/journal.pone.0091574

Yegutkin, G.G., Guerrero-Toro, C., Kilinc, E., Koroleva, K., Ishchenko, Y., Abushik, P., Giniatullina, R., Fayuk, D., Giniatullin, R., 2016. Nucleotide homeostasis and purinergic nociceptive signaling in rat meninges in migraine-like conditions. Purinergic Signal. 12, 561-574. https://doi.org/10.1007/s11302-016-9521-8

Yücel, M., Kotan, D., Çiftçi, G.G., Çiftçi, I.H., Cikriklar, H.I., 2016. Serum levels of endocan, claudin-5 and cytokines in migraine. Eur. Rev. Med. Pharmacol. Sci. 20, 930936.

Zakharov, A., Koroleva, K., Giniatullin, R., 2016. Clustering Analysis for Sorting ATPInduced Nociceptive Firing in rat Meninges. Bionanoscience 6, 508-512. 


\section{Meningeal lymphatics in migraine}

https://doi.org/10.1007/s12668-016-0276-z

Zakharov, A., Vitale, C., Kilinc, E., Koroleva, K., Fayuk, D., Shelukhina, I., Naumenko, N., Skorinkin, A., Khazipov, R., Giniatullin, R., 2015. Hunting for origins of migraine pain: cluster analysis of spontaneous and capsaicin-induced firing in meningeal trigeminal nerve fibers. Front. Cell. Neurosci. 9, 287. https://doi.org/10.3389/fncel.2015.00287

\section{Figure Legend}

Figure 1. Migraine-related cell types and active mediators present in meninges. The main migraine mediator CGRP is released from the meningeal trigeminal nerve fibers, whereas ATP, serotonin (5-HT) and cytokines are released from local immune cells, including mast cells. We propose that the local lymphatic system, which supposedly contributes to meningeal drainage, maintain local homeostasis preventing the accumulation of pro-inflammatory and pronociceptive compounds.

Figure 2. Dural mast cells in WT and K14 mice lacking the lymphatics. Mast cells localize in meninges in both WT (A) and K14 mice (B). Note the presence of mast cells (red triangles) aligned along the blood vessels (outlined with black dashed curves). (C) Mast cells were counted in WT and K14 animals. Transgenic animals show a non-significant trend towards a larger number of mast cells $(1055 \pm 40$ cells in WT vs. $1177 \pm 56$ cells in K14, $\mathrm{n}=$ 8/experimental group, Mann-Whitney $\mathrm{U}=16.5, \mathrm{p}=0.1089$ by Mann-Whitney $\mathrm{U}$ test). Scale bar $=200 \mu \mathrm{m}$.

Figure 3. Baseline cytokines release from meninges. Concentrations $(\mathrm{pg} / \mathrm{ml})$ of following cytokines are depicted: IL-6 (A), IL-10 (B), MCP-1 (C), TNF $\alpha$ (D), IL-12p70 (E) and IFN $\gamma$ (F). In K14 animals, we found a significant increase in the levels of MCP-1 (C) $(829 \pm 48$ $\mathrm{pg} / \mathrm{ml}$ in WT vs. $1061 \pm 72 \mathrm{pg} / \mathrm{ml}$ in K14, Mann-Whitney $\mathrm{U}=11$, \#p = 0.0281, Mann-Whitney $\mathrm{U}$ test), whereas the levels of IL-12p70 (E) were significantly lower compared to the one measured in WT littermates $(3.5 \pm 0.5 \mathrm{pg} / \mathrm{ml}$ in WT vs. $1.8 \pm 0.2 \mathrm{pg} / \mathrm{ml}$ in K14, Mann-Whitney $\mathrm{U}=1.0, \# \# \mathrm{p}=0.0023$, Mann-Whitney $\mathrm{U}$ test). No difference was found for other interleukines. Number of replicates for IL-6, IL-10, MCP-1 and TNF $\alpha$ analysis $n=8$ /experimental group; for IL-12p70 analysis: $\mathrm{n}=7$ and 6 for WT and K14, respectively; for IFN $\gamma$ analysis: $\mathrm{n}=5$ and 6 for WT and K14, respectively.

Figure 4. Cytokines release from meninges after BzATP stimulation. Scatter plots reporting the concentrations of cytokines released from meningeal preparation after stimulation with BzATP: IL-6 (A), IL-10 (B), MCP-1 (C), TNFa (D), IL-12p70 (E) and IFN $\gamma$ (F). BzATP induced an increase in the release of IL-10 (B) (treatment effect WT- K14-control vs. WT- 


\section{Meningeal lymphatics in migraine}

707 K14-BzATP, $\mathrm{F}(1,14)=35.75, * * * \mathrm{p}<0.0001$ by matched two-way ANOVA) and TNF $\alpha(\mathbf{D})$

708 (WT- K14-control vs. WT- K14-BzATP, $\mathrm{F}(1,14)=12.43, * * \mathrm{p}=0.0034$ by matched two-way 709 ANOVA). Post-hoc comparisons revealed that IL-10 increase did not differ between WT and

$710 \mathrm{~K} 14$, whereas BzATP-stimulated release of TNF $\alpha$ was significant only in the WT mice $(55 \pm$ $71118 \mathrm{pg} / \mathrm{ml}$ in WT-control vs. $112 \pm 23 \mathrm{pg} / \mathrm{ml}$ in WT-BzATP, $\mathrm{t}(14)=2.933, * \mathrm{p}=0.0218$ by 712 Bonferroni post-hoc test). Number of replicates for IL-6, IL-10, MCP-1, TNF $\alpha$ analysis: $\mathrm{n}=$ 713 8/experimental group; for IL-12p70 analysis: $n=7$ and 6 (control) and $n=5$ and 6 (BzATP) 714 for WT and K14, respectively; for IFN $\gamma$ analysis: $n=5$ and 6 (control) and $n=4$ and 5 (BzATP) 715 for WT and $\mathrm{K} 14$, respectively.

716 Figure 5. CGRP released from trigeminal nerve endings in the meninges, from hemiskull 717 preparation. (A) CGRP release was not altered in K14 hemiskulls under basal conditions: 24 $718 \pm 4 \mathrm{pg} / \mathrm{ml}$ in WT-BL1 vs. $20 \pm 3 \mathrm{pg} / \mathrm{ml}$ in K14-BL1, and $25 \pm 3 \mathrm{pg} / \mathrm{ml}$ in WT-BL2 vs. $17 \pm 2$ $719 \mathrm{pg} / \mathrm{ml}$ in K14-BL2 ( $=7 /$ experimental group, $\mathrm{p}>0.05$ by matched two-way ANOVA with 720 Bonferroni post-hoc test). The application of $30 \mathrm{mM} \mathrm{KCl}$ triggered a significant increase in the 721 CGRP level in both genotypes (treatment effect: $\mathrm{F}(2,24)=103.3$, ***p $<0.0001$ by matched 722 two-way ANOVA, $\mathrm{n}=7$ /experimental group). Overall CGRP release was higher in WT 723 animals (genotype effect: $\mathrm{F}(1,12)=6.025$, \#p $=0.0303$ by matched two-way ANOVA). Post724 hoc comparisons revealed that the concentration of the released CGRP under the stimulation 725 was significantly lower in the hemiskulls lacking the lymphatic system compared to the WT 726 preparations $(94 \pm 16 \mathrm{pg} / \mathrm{ml}$ in $\mathrm{K} 14-\mathrm{KCl} v s .138 \pm 11 \mathrm{pg} / \mathrm{ml}$ in $\mathrm{WT}-\mathrm{KCl} ; \mathrm{t}(36)=3.816$, \#\#p = 7270.0015 by Bonferroni post-hoc test, $\mathrm{n}=7 /$ experimental group). (B) We propose two possible 728 explanations for the altered CGRP release: (1) lower density of trigeminal afferents releasing 729 CGRP, or (2) lower expression of CGRP.

730 Figure 6. Direct spikes were recorded in WT and K14 hemiskulls under basal conditions and ATP stimulation. (A) Sample traces of nociceptive recordings in WT and K14 animals under basal and stimulated conditions. (B) The plot represents number of nociception-related

733 spikes recorded in 5 minutes (median with interquartile range) under basal conditions, during 734 the application of $100 \mu \mathrm{M}$ ATP, and during the following washout. ATP induced a significant increase in nociception activity in both genotypes (baseline $v s$. ATP, $\mathrm{t}(50)=-2.65,{ }^{*} \mathrm{p}=0.0107$ by linear mixed-effects model; $n=6$ /experimental group).

737 Figure 7. Segmentation analysis of meningeal innervation. (A) A representative image of 738 meninges stained for $\beta$-tubulin III (white), segmented for morphological analyses. Blue lines 739 represent axons, and yellow filled-circle represent terminal points (i.e., CGRP-releasing 740 trigeminal fiber terminal endings). (B) Scatter plot depicting the total axonal length (axons 741 highlighted with blue on panel A): $37 \pm 5 \mathrm{~mm}$ in WT vs. $35 \pm 4 \mathrm{~mm}$ in K14, Mann-Whitney U

$742=47, \mathrm{p}=0.8534$ by Mann-Whitney U test test. (C) Scatter plot depicting the number of terminal 743 points (yellow dots on panel A): $109 \pm 10$ in WT vs. $127 \pm 11$ in K14, Mann-Whitney U = 32.5, 


\section{Meningeal lymphatics in migraine}

$744 \mathrm{p}=0.1972$ by Mann-Whitney $\mathrm{U}$ test. We analyzed meningeal innervation from the right

745 hemiskulls of 10 independent animals in each experimental group (WT and K14; one image

746 per animal).

747 Figure 8. Experimental findings summary. Dysfunctional lymphatic system triggered

748 alterations in migraine mediator levels in the meninges. Number of mast cells was increased,

749 supported by increased level of mast cell-activating cytokine MCP-1. CGRP release was

750 decreased, supported by decreased level of TNF $\alpha$, a cytokine triggering CGRP transcription.

751 The level of the pro-inflammatory IL-12p70 was decreased as well. Trigeminal innervation of

752 the meninges and trigeminal nociception were not changed. Red indicates pro-inflammatory

753 and pro-nociceptive changes, green indicates anti-inflammatory and anti-nociceptive changes.

754 Arrow up $(\uparrow)$ indicates an increase in the parameter, arrow down $(\downarrow)-$ decrease, equals sign

755 (=) indicates unchanged parameters. 


\section{Meninges}

\section{Inflammation}

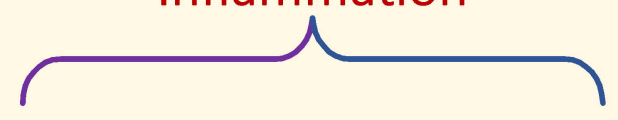

Mast cell

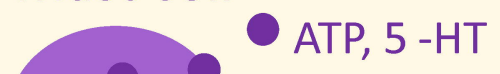
cytokines -

Functional $\mathrm{mLVs}$ Drainage CGRP

O
Trigeminal neuron

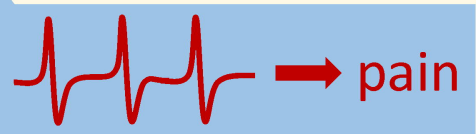




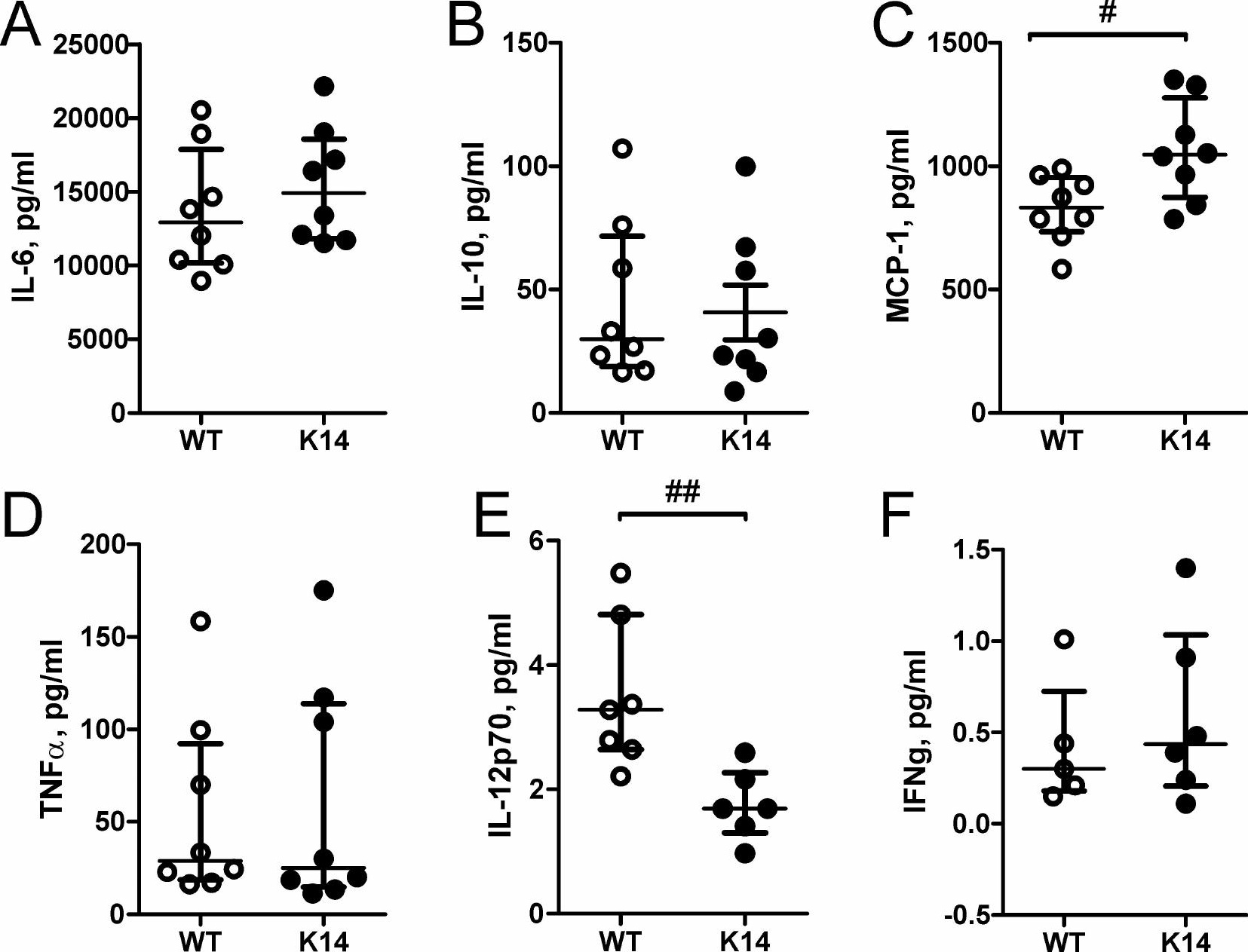




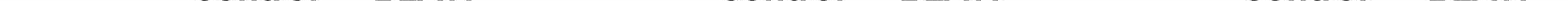




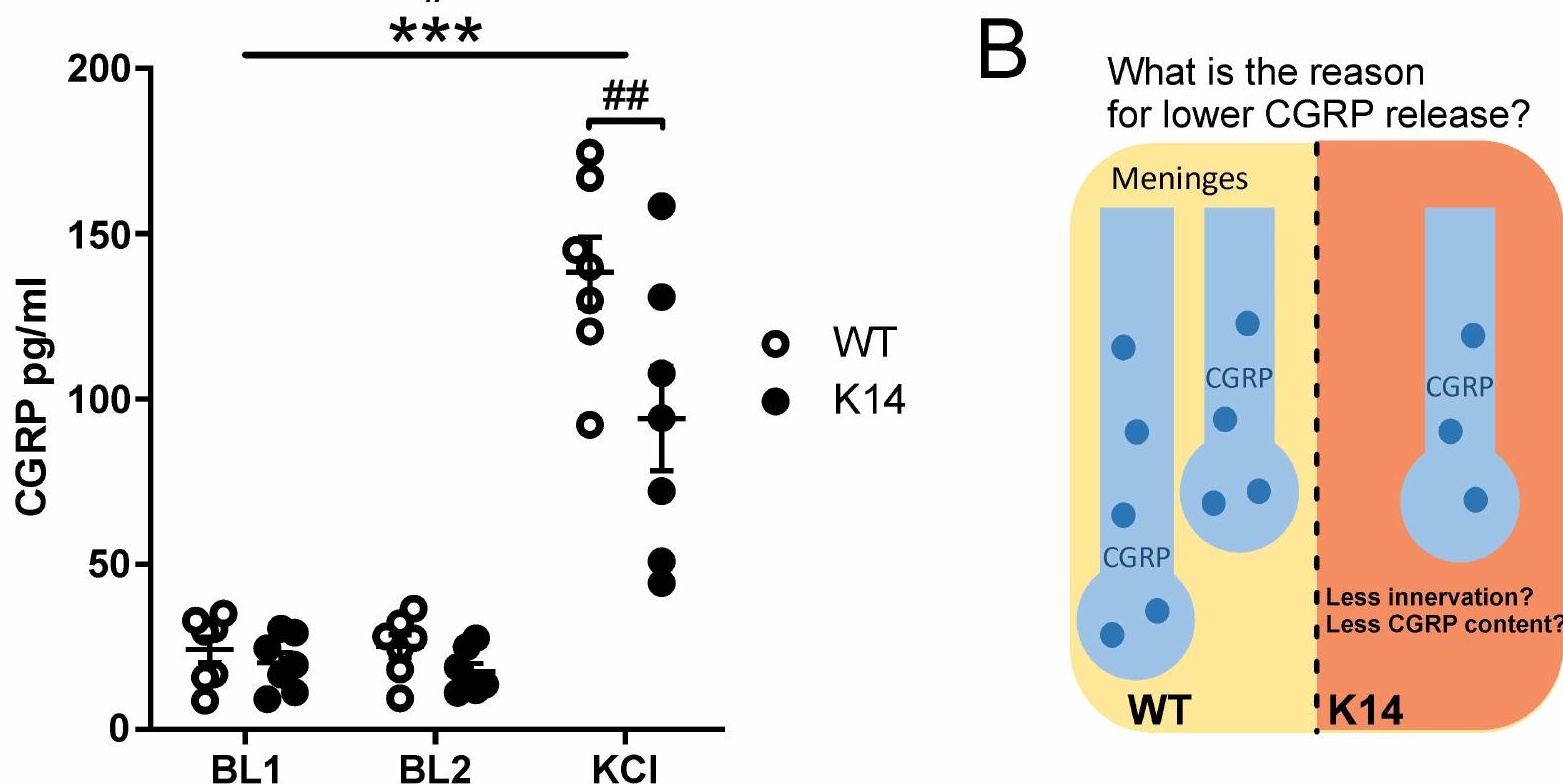



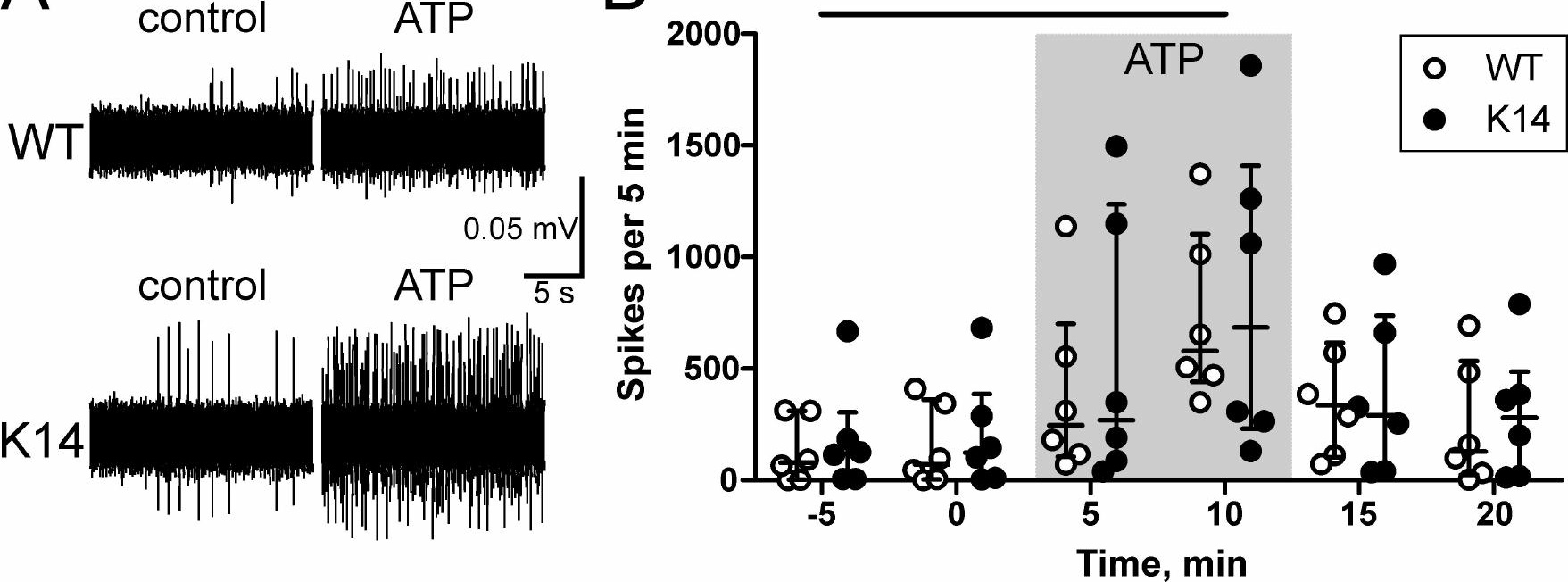

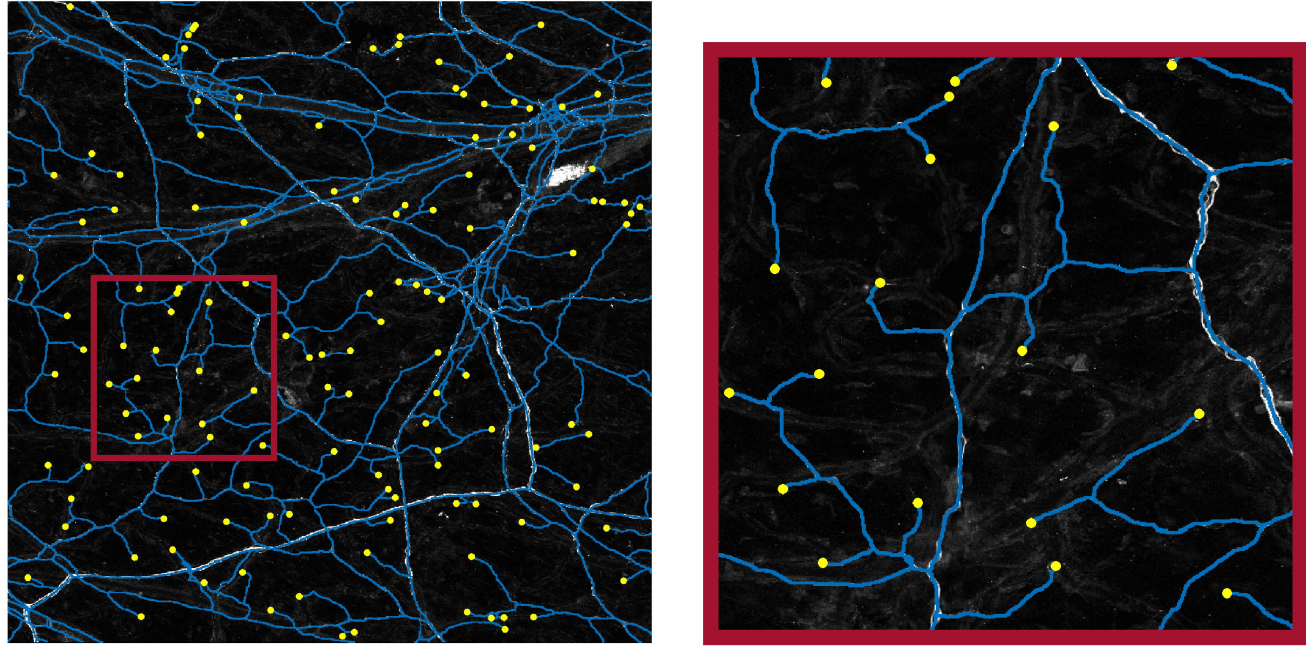

$B$
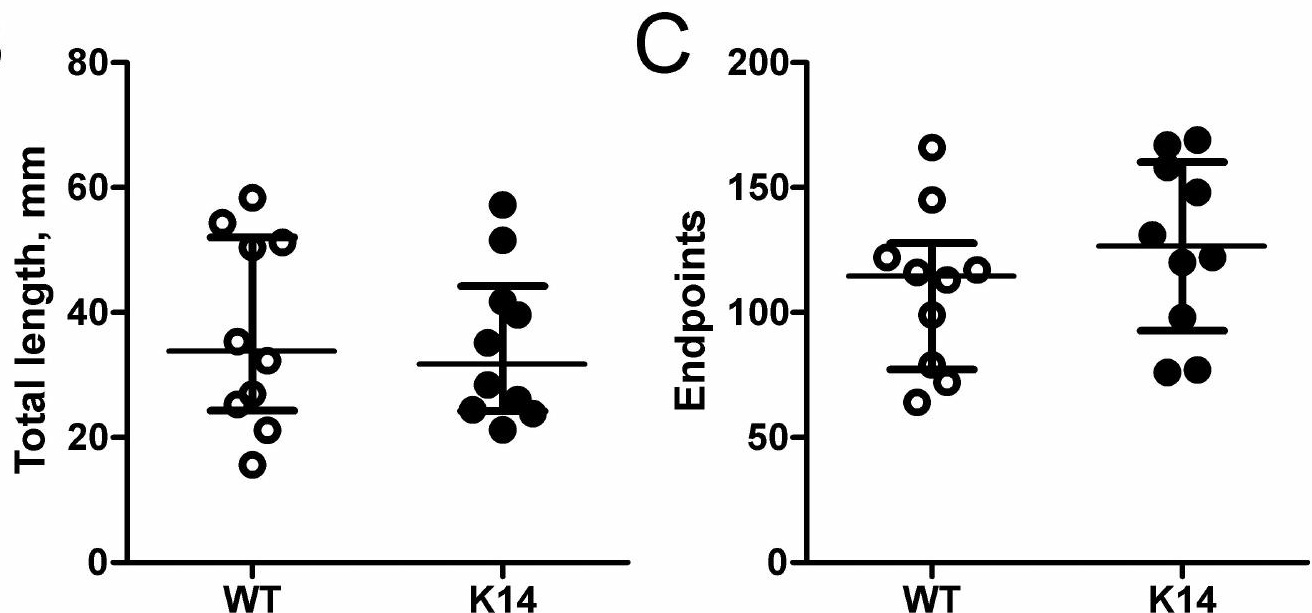


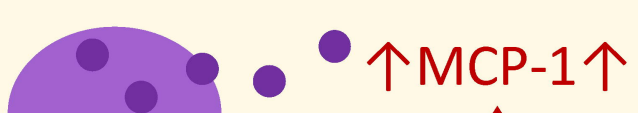

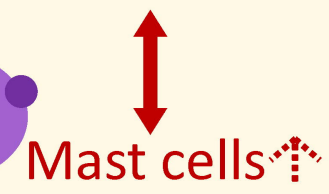

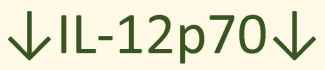

$\downarrow T N F \alpha \downarrow$

= Nociception $=$

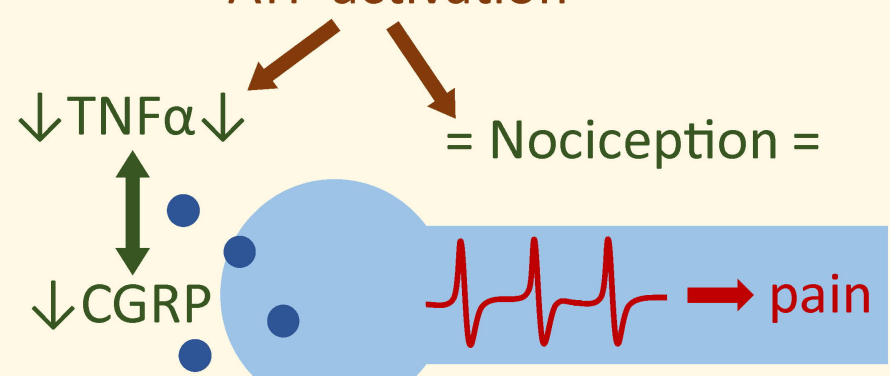

=Trigeminal innervation=

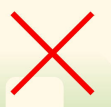

Non-functional mLVs 